\title{
PERANCANGAN VISUAL BOOK SEJARAH POS DI INDONESIA MASA PRA-REPUBLIK HINGGA KEMERDEKAAN REPUBLIK INDONESIA
}

\author{
Yuniar Arya Pradipta \\ Program Studi Desain Komunikasi Visual \\ Fakultas Seni Rupa ISI Yogyakarta
}

\begin{abstract}
One thing that is very important in the struggle to liberate Indonesia from the hands of the invaders is a Telecommunication service. At that time the Bureau of Post, Telegraph and Telephone (PTT) has a great role to provide these facilities. Pos Indonesia is already 268 years devoted to telecommunications services, starting from the first post office was established by the Governor General GW Baron van Imhoff on August 26, 1746 in Batavia.

Because it has particularly high historical value and has a great contribution to the independence of the Indonesian nation, the postal history is very important to be re-introduced. One way to re-introduce the historical event is to provide a source of reference in the form of books, remembering that a book talking about the history of Indonesian Postal in a practical and informative way still rare.

In order to design practical and easy to understand book, visual book such as a media of visual communication chosen to deliver the history of of Indonesian Postal information. In order to make visual book visually attractive and easy to understand, the chosen is vector art illustration in the style of flat design. Data about the history of Indonesian Postal which will be used as a history source of visual book in advance filtered by how important and interesting the historical events and re-ordered according timeline. Then the collected data are illustrated with the vector art style and lay-outed to produce a simple and informative visual book.
\end{abstract}

Keywords: Visual Book, Postal History, Indonesia, Pre-Republic, Independence of the Republic of Indonesia, Vector Art, Flat Design

\section{A. PENDAHULUAN}

\section{Latar Belakang Masalah}

Surat-menyurat merupakan salah satu cara manusia untuk mengirimkan baik informasi maupun benda ke tempat-tempat yang dituju dengan menggunakan layanan dari badan yang bertugas melakukan pengiriman tersebut. Indonesia telah mengenal dunia surat-menyurat sejak zaman kerajaan. Berdasarkan catatan sejarah, kegiatan surat menyurat sudah dimulai sebelum kedatangan bangsa Eropa ke Nusantara (Indonesia), yaitu pada masa Kerajaan Kutai, Tarumanegara,
Pajajaran, Majapahit, Sriwijaya, dan Mataram. Hubungan komunikasi yang terjalin pada masa kerajaan-kerajaan itu memang hanya terbatas pada hubungan antar raja saja. Bentuknya masih sangat sederhana. Para raja itu menggunakan kulit kayu, potongan bambu, daun lontar, dan kulit binatang untuk berkirim surat/pesan. (http://www.posindonesia.co.id/index.php/pr ofil-perusahaan/sejarah-pos, diakses pada 13 Mei 2014 )

Setelah bangsa Eropa masuk ke kawasan Nusantara, kegiatan surat menyurat berkembang dengan menggunakan media 
kertas. Mereka juga mengenalkan sebuah jasa pengiriman surat yang dinamakan Kantor Pos. Kantor Pos pertama didirikan di Batavia (sekarang Jakarta) oleh Gubernur Jendral G.W Baron van Imhoff pada tanggal 26 Agustus 1746 dengan tujuan untuk lebih menjamin keamanan surat-surat penduduk, terutama bagi mereka yang berdagang dari kantor-kantor di luar Jawa dan bagi mereka yang datang dari dan pergi ke Negeri Belanda. Sejak itulah pelayanan pos telah lahir mengemban peran dan fungsi pelayanan kepada publik. (http://www.kidnesia.com/Kidnesia2014/Dari -Nesi/Sekitar-Kita/Pengetahuan-

Umum/Surat-Menyurat-di-Indonesia, diakses pada 13 Mei 2014 )

Dalam Sejarah PT.Pos Indonesia telah kita ketahui bahwa badan usaha ini telah beberapa kali mengalami perubahan status mulai dari Jawatan PTT (Post, Telegraf dan Telefon). Badan usaha yang dipimpin oleh seorang Kepala Jawatan ini operasinya tidak bersifat komersial dan fungsinya lebih diarahkan untuk mengadakan pelayanan publik. Perkembangan terus terjadi hingga statusnya menjadi Perusahaan Negara Pos dan Telekomunikasi (PN Postel). Mengamati perkembangan zaman dimana sektor pos dan telekomunikasi berkembang sangat pesat, maka pada tahun 1965 berganti menjadi Perusahaan Negara Pos dan Giro (PN Pos dan Giro), dan pada tahun 1978 berubah menjadi Perum Pos dan Giro yang sejak ini ditegaskan sebagai badan usaha tunggal dalam menyelenggarakan dinas pos dan giropos baik untuk hubungan dalam maupun luar negeri. Selama 17 tahun berstatus Perum, maka pada Juni 1995 berubah menjadi Perseroan Terbatas dengan nama PT Pos
Indonesia

(Persero)

(http://www.posindonesia.co.id/index.php/pr ofil-perusahaan/sejarah-pos, diakses pada 13 Mei 2014)

Pos Indonesia merupakan perusahaan BUMN yang memiliki nilai historis yang tinggi. Seiring perjalanan sejarah yang panjang, kontribusi PT.Pos Indonesia sangatlah besar, sudah 268 tahun PT.Pos Indonesia mengabdi untuk menyediakan jasa surat-menyurat sebagai media komunikasi masyarakat Indonesia jarak dekat maupun jauh. Selain itu Pos Indonesia juga memiliki peran penting dalam membantu pengumpulan dana dari rakyat untuk pembangunan Negara Indonesia pada awal masa kemerdekaan Indonesia.

Pada masa Hindia Belanda, tepatnya pada tahun 1933 didirikan museum Pos Indonesia dengan nama Museum PTT (Pos Telegrap dan Telepon) di kota Bandung. Pembangunan museum ini bertujuan agar warisan sejarah yang terkandung di dalam benda-benda Pos itu tetap terpelihara dan dikenal oleh generasi-generasi penerus. Museum yang dirancang oleh arsitek Ir. J. Berger dan Leutdsgebouwdienst dengan gaya arsitektur Italia masa Renaissance berfungsi sebagai sebuah tempat yang mengoleksi dan memelihara sejumlah benda yang memiliki nilai sejarah dalam perjalanan Perusahaan Pos Indonesia sejak masa Hindia Belanda, masa pendudukan Jepang, masa kemerdekaan, hingga sekarang ini, baik dalam bentuk foto, maket, lukisan, katalog, dan peralatan pos lainnya (http://www.1001malam.com/surrounding/37 7/bandung/museum-pos-indonesia.html, diakses pada 14 Mei 2014) 
Pada saat ini teknologi internet telah menjadi bagian hidup sehari-hari membuat Pos di Indonesia semakin jauh dari generasi muda apalagi mengetahui sejarahnya menggunakan jasa Pos sendiri bisa dikatakan jarang. Selain itu manajer museum Pos Indonesia Tenan Priyo Widodo menyatakan bahwa tampilan antik Museum Pos Indonesia dan kurangnya informasi yang terdapat di dalamnya membuat generasi muda, khususnya anak-anak dan remaja muda, merasa bosan sehingga tidak terlalu tertarik untuk mengeksplor lebih jauh tentang rahasia sejarah Pos Indonesia di museum (Evelyn, 2011:1). Kurangnya minat bagi generasi muda terutama remaja terhadap sejarah pos di Indonesia sangatlah disayangkan mengingat potensi sejarah yang besar yang dimiliki Pos Indonesia. Hal tersebut seirama dengan apa yang disimpulkan oleh Kemendikbud, Dirjen Kebudayaan, Direktorat Sejarah dan Nilai Budaya dalam buku Pemikiran Tentang Pembinaan Kesadaran Sejarah bahwa pada umumnya kesadaran sejarah di kalangan masyarakat masih sangatlah rendah, hal tersebut selain dikarenakan kurangnya tenaga pengajar juga karena masih kurangnya media penunjang dan referensi sejarah Indonesia (Kemendikbud, Dirjen Kebudayaan, Direktorat Sejarah dan Nilai Budaya, 2012: 62-63).

Pos Indonesia berkerjasama dengan BTN mendirikan tabungan tanpa biaya administrasi bulanan yang bernama e'Batarapos Tabungan melaui kantor pos ini sangat membantu bagi masyarakat dengan ekonomi menengah ke bawah di Indonesia. (www.posindonesia.co.id/index.php/produk/j asa-keuangan/bank-chanelling, diakses pada 14 Mei 2014). Seperti yang telah dialami oleh penulis yang selama ini merasa sangat terbantu dengan jasa tabungan tersebut. Orang tua penulis bisa menabung tanpa dibebani biaya administrasi bulanan melalui kantor Pos. Dengan menabung di Pos Indonesia, orang tua penulis dapat membantu biaya hidup dan pendidikan untuk kuliah di ISI Yogyakarta, disamping itu juga mendapatkan biaya hidup dan pendidikan dari beasiswa Bidik Misi. Selain tabungan, Orang tua penulis juga melakukan pengiriman uang melalu Weselpos instant. Wesselpos instant dipilih karena disamping orang tua penulis melakukan penyimpanan uang di kantor Pos, jasa ini dipih karena cepat dan cara pengambilan uang yang mudah yaitu hanya dengan menunjukkan nomor pin dan meninggalkan fotocopy KTP sebagai bukti pengambilan. Karena cukup sering pergi ke kantor Pos pada saat mengambil kiriman uang, penulis menyadari betapa berjasanya lembaga ini, dan memiliki potensi sejarah yang besar karena telah berdiri sejak 268 tahun yang lalu, jauh sebelum Indonesia merdeka, dan selama ini penulis juga belum menjumpai buku sejarah Pos di Indonesia yang praktis dan informatif. Dikarenakan hal tersebut penulis mendapatkan ide dan berkeinginan untuk membuat buku ilustrasi yang memberikan pengetahuan tentang sejarah yang telah dilalui oleh lembaga ini.

Agar buku yang dibuat tidak membosankan dan menarik untuk dibaca maka dengan memanfaatkan ilmu komunikasi visual yang selama ini telah dipelajari, akan dirancang buku tersebut dalam bentuk visual book yang akan mengilustrasikan pengetahuan sejarah tersebut dengan media ilustrasi. Ilustrasi adalah hasil visualisasi dari suatu tulisan 
dengan teknik drawing, lukisan, fotografi, atau teknik seni rupa lainnya yang lebih menekankan hubungan subjek dengan tulisan yang dimaksud daripada bentuk. Tujuan ilustrasi adalah untuk menerangkan atau menghiasi suatu cerita, tulisan, puisi, atau informasi tertulis lainnya. Diharapkan dengan bantuan visual, tulisan tersebut lebih mudah dicerna.

Di sisi lain, pada era kemajuan teknologi dan komunikasi telah banyak membawa kemajuan dalam seni ilustrasi. Dengan munculnya berbagai macam software ilustrasi di komputer, banyak juga bermunculan berbagai jenis ilustrasi digital mulai dari yang berformat bitmap maupun vector. Hal ini memudahkan kita untuk bereksplorasi untuk membuat media komunikasi visual yang unik dan menarik melalui media ilustrasi digital. Karena faktor tersebut, penulis bermaksud menggunakan media ilustrasi untuk menyampaikan sejarah Pos di Indonesia, karena memiliki nilai historis yang tinggi disamping itu Pos memiliki jasa yang besar bagi bagsa Indonesia.

\section{Rumusan Masalah}

Bagaimana merancang visual book sejarah Pos di Indonesia masa pra-republik hingga kemerdekaan Republik Indonesia secara menarik dan informatif?

\section{Tujuan Perancangan}

Tujuan dalam perancangan visual book sejarah Pos Indonesia

a) Merancang Visual book sebagai media pembelajaran dan referensi tentang sejarah pos di Indonesia

b) Merancang Visual book yang menarik dan informatif bagi target audience pelajar usia sekolah menengah hingga mahasiswa (17-27 tahun) serta masyarakat umum.

c) Merancang ilustrasi dan komponen visual dari visual book sejarah Pos di Indonesia

\section{Teori dan metode}

\section{a) Teori Visual Book Sejarah Pos}

1) Pengertian Visual

Pengertian dari kata visual mengacu kepada bentuk atau objek yang dapat dilihat oleh indra pengelihatan yaitu mata. Arti kata visual dalam bahasa inggris adalah: berdasarkan pengelihatan, dapat dilihat (Widiastutik S. Daryanto Sigit 1991:200). Sedangkan kata visual sendiri diserap kedalam bahasa Indonesia juga memiliki memiliki arti yang sama : Berdasarkan penglihatan mata (S.S. Daryanto 1997:626).

Dari pengertian visual di atas dapat diartikan bahwa suatu objek yang ditangkap oleh indra pengelihat atau mata itulah yang disebut dengan visual.

2) Pengertian Book

Dalam bahasa Indonesia kata book sama artinya dengan buku/kitab yang berarti: bendel lembar kertas, lembar kertas yang berjilid, kitab, bendel kertas yang bertuliskan disiplin ilmu tertentu (S.S. Daryanto 1997:116).

3) Sintesa Pengertian Visual Book Sejarah

Penyajian buku dalam bentuk visual book kebanyakan kita jumpai digunakan untuk buku-buku pengetahuan maupun hiburan untuk 
anak dan remaja, meskipun ada juga yang diperuntukkan untuk pembaca dewasa. Dari buku-buku tersebut kebanyakan penyajiannya didominasi oleh unsur visual yang berupa gambar ilustrasi namun juga dilengkapi teks sebagai pelengkap. Buku sejarah yang disajikan dalam bentuk visual book memiliki gaya penyajian yang berbeda beda, ada yang menggunkan ilustrasi kartun, ilustrasi dengan gambar naturalis, hingga yang menggunakan cerita dan dialog agar lebih menarik.

\section{4) Perihal Sejarah Pos}

Secara umum Pos memiliki arti organisasi yg menyelenggarakan kirim-mengirim barang, surat, uang, d-s-b. Lebih jelasnya yang dimaksud dengan pos adalah bagian dari sistem atau metode yang digunakan untuk mengirimkan informasi atau objek yang bisa berupa dokumen tertulis yang biasanya dikirim dengan menggunakan amplop tertutup dan perangko sebagai bukti pembayaran, dan paket untuk benda-benda lain yang pengirimannya bisa menjangkau seluruh wilayah di dunia (http://www.artikata.com/arti-345775pos.html, diakses pada 23 Mei 2014).

Dari uraian diatas dapat disimpulkan bahwa yang dimaksud dari sejarah pos adalah sejarah dari surat-menyurat atau bisa juga berarti sejarah dari organisasi yang melayani pengiriman surat maupun barang sebagai salah satu bentuk komunikasi dan layanan publik.

\section{b) Metode Analisis}

Metode analisis data yang digunakan dalam perancangan ini adalah metode analisis $5 \mathrm{w} 1 \mathrm{~h}$. Dengan metode ini diharapkan dapat menggali informasi lebih mendalam pada setiap akar permasalahan yang dihadapi.

1) What:

Menyampaikan sejarah Pos di Indonesia melalui visual book

2) Who:

Pos Indonesia

3) Where:

Di wilayah negara Indonesia

4) When:

Zaman awal surat menyurat, terutama sejak masuknya bangsa belanda, hingga zaman kemerdekaan Indonesia

5) Why:

Pos Indonesia menyimpan potensi sejarah yang besar dan jasa yang besar bagi bangsa Indonesia.

\section{B. KONSEP \\ 1) Konsep Karya}

Sejarah Pos di Indonesia masih belum banyak diketahui oleh masyarakat Indonesia karena masih kurangnya buku yang membahas tentang sejarah tersebut. Untuk mengatasi hal tersebut diperlukan adanya buku yang membahas sejarah Pos Indonesia yang menarik bagi udience pada saat ini. Agar target audience dapat tertarik terhadap sejarah Pos di Indonesia, maka dalam buku ini akan dibahas jasa-jasa bagi bangsa Indonesia pada baik pada masa sebelum 
maupun sesudah perang kemerdekaan. Karena dengan mengenal lebih dekat sejarah dan jasa Pos di Indonesia maka akan timbul jiwa patriotisme yang sangat penting bagi kemajuan Bangsa dan Negara Indonesia.

Untuk mempermudah dalam pembelajaran Sejarah Pos di Indonesia, diperlukan buku yang dapat menyapaikan sejarah Pos di Indonesia secara sederhana dan menarik. Penyederhanaan tersebut dapat berupa perangkuman sejarah-sejarah yang penting dan berpengaruh pada sejarah Pos di Indonesia pada masa sebelum maupun setelah perang kemerdekaan dengan menggunkan timeline sejarah yang jelas dan runtut. Sealin itu, dalam penyampaian pada masing-masing peristiwa sejarah yang terjadi juga harus dilakukan dengan cara yang sederhana, mudah dimengerti, dan tetap terlihat menarik. Sehingga untuk mengatasinya digunakanlah gambar ilustrasi untuk memperagakan peristiwa sejarah yang terjadi, karena gambar adalah bahasa universal yang dapat dimengerti oleh semua orang.

Untuk menghasilkan ilustrasi yang menarik dan diminati, maka pemilihan gaya ilustrasi harus sesuai dengan perkembangan trend ilustrasi yang ada. Pada saat mulai bermunculan desain-desain dengan gaya flat design UI yang sederhana namun terlihat menarik dan berbeda dari gaya desain lainnya. Gaya desain ini banyak bermunculan pada website maupun aplikasi-aplikasi smartphone dan cukup menjadi trend pada saat ini. Selain itu penerapan gaya desain ini pada ilustrasi juga memiliki beberapa keuntungan antara lain: desain cenderung sederhana sehingga mempercepat penyampaian pesan visual pada audience dan akan terlihat unik, karena merupakan gaya desain yang relatif masih baru dan sebagian besar diterapkan pada web maupun aplikasi maka gaya desain ini masih jarang digunakan sebagai ilustrasi buku. Terdapat beberapa cara dalam membuat desain ini baik yang berupa image bitmap maupun vector, namun ilustrasi vector dipilih karena lebih menguntungkan dalam membuat objek-objek sederhana dan geometris dengan warna yang block.

\section{2) Sinopsis Karya}

Sudah 268 tahun Pos Indonesia mengabdi untuk pelayanan telekomunikasi, terhitung sejak kantor pos pertama didirikan oleh Gubernur Jendral G.W Baron van Imhoff pada tanggal 26 Agustus 1746 di Batavia. Namun diluar semua itu, bentuk Perposan yang sederhana di Indonesia sudah dikenal sejak masa kerajaan. Indonesia telah mengenal dunia surat-menyurat sejak zaman kerajaan. Berdasarkan catatan sejarah, kegiatan surat menyurat sudah dimulai sebelum kedatangan bangsa Eropa ke Nusantara (Indonesia), yaitu pada masa Kerajaan Kutai, Tarumanegara, Pajajaran, Majapahit, Sriwijaya, dan Mataram.

Setelah kedangan penjajah bentuk perposan tersebut dibuat semakin melembaga untuk menjamin kemudahan berkomunikasi dengan negara asalnya. Perkembangan teknologi membuat lembaga perposan menjadi semakin luas dan tidak hanya sebatas komunikasi surat menyurat, yaitu merambah ke komunikasi dengan telegraf dan telepon, sehingga lembaga pos pada masa tersebut disebut dengan jawatan Pos, telegraf, dan Telepon (PTT). Jawatan inilah yang sangat berjasa untuk perjuangan bangsa Indonesia 
untuk melawan penjajah, setelah kantor pusat PTT di Bandung berhasil diambil alih. Saat berita menyerahnya Jepang kepada sekutu disiarkan PTT-lah yang berjasa pertama kali mengetahuinya dan langsung menyebarluaskannya, hingga proklamasi kemerdekaan Indonesia dikumandangkan PTT juga yang sangat berjasa untuk menyebarluaskannya ke seluruh pelosok negara Indonesia dan ke negara lainnya untuk mengukuhkan kedaulatan dan kemerdekaan bangsa Indonesia. jawatan PTT inilah yang pada saat ini kita ketahui sebagai Pos Indonesia.

\section{A. Karya Visual Book}

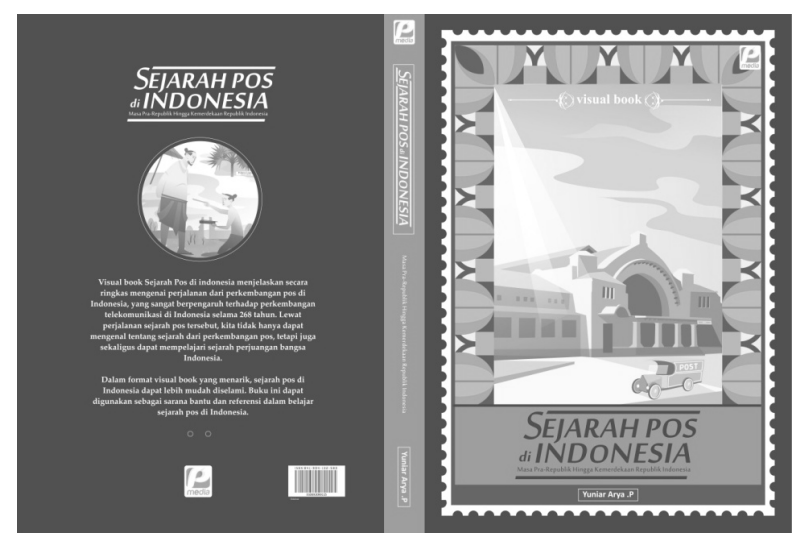

Gambar 1 Cover buku Sumber: Yuniar A.P.

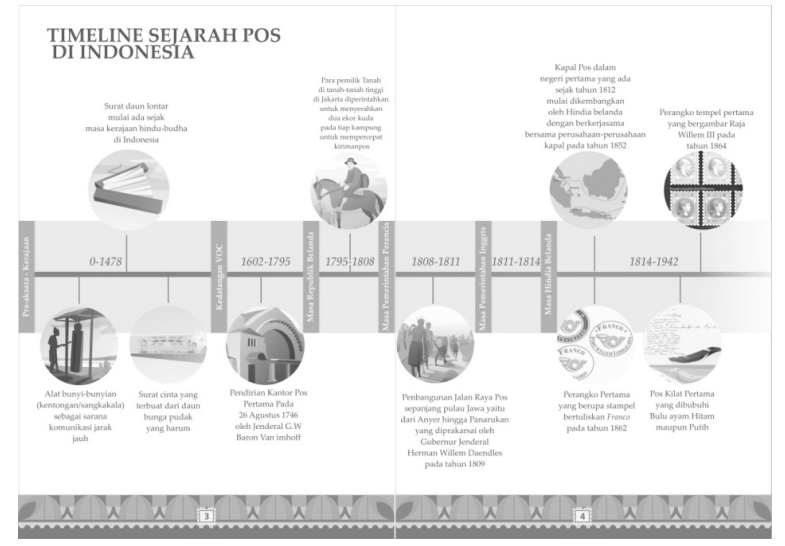

Gambar 2 Timeline sejarah Pos Sumber: Yuniar A.P.
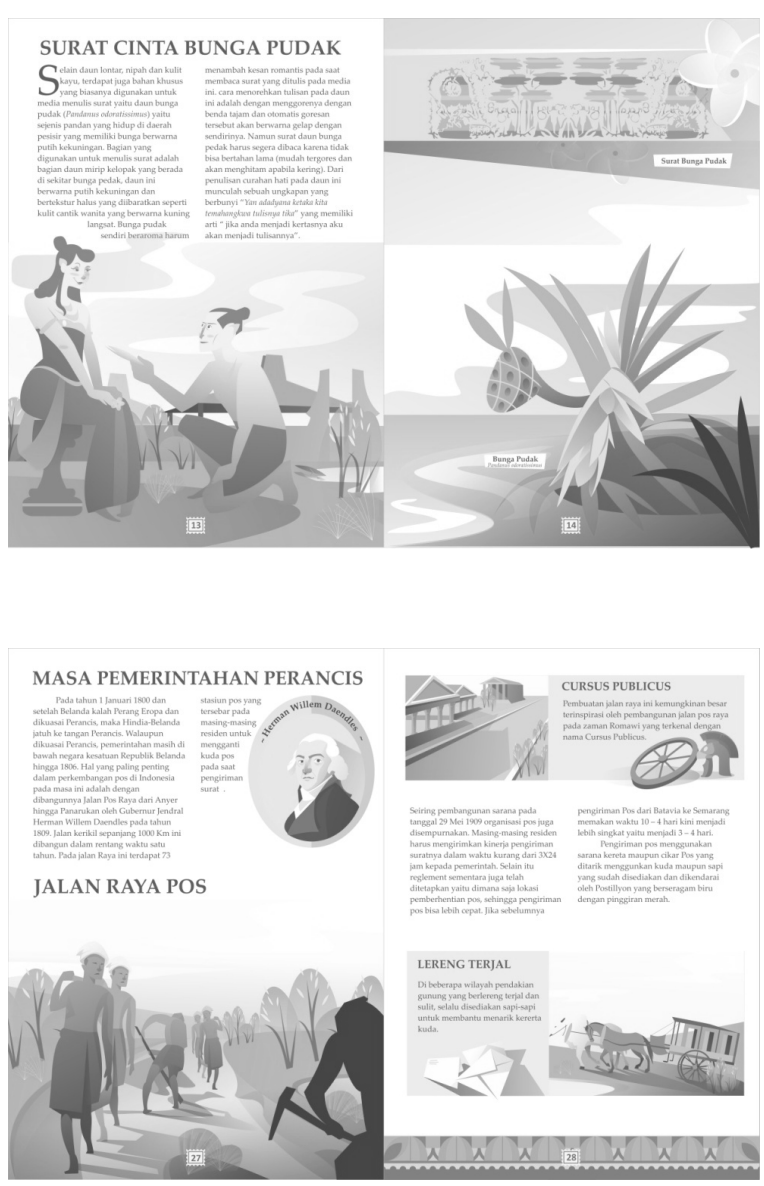

Gambar 3 Ilustrasi buku Sumber: Yuniar A.P.

\section{KESIMPULAN}

Bangsa Indonesia dapat menjadi bangsa yang besar dan merdeka seperti saat ini tidak lepas dari jasa dan pengorbanan para pendahulu kita yang berjuang mati-matian untuk melepaskan diri dari cengkraman penjajah. Dengan mengetahui akar sejarah kita sebagai bangsa Indonesia dapat membuat kita menjadi bukan hanya sekedar manusia biasa yang sekedar hidup di bumi, melainkan sebuah pencapaian dari peradaban serta perjuangan para pahlawan.

Pos di Indonesia memiliki jasa yang besar dalam meyediakan sarana komunikasi 
jarak jauh terutama saat perang kemerdekaan. Salah satu contohnya adalah, jawatan Pos, Telepon, dan telegraf, (PTT) memiliki peranan yang penting dalam mendapatkan informasi kekalahan Jepang melalui gelombang radio, dan pada saat proklamasi dikumandangkan PTT berjasa untuk menyebar luaskan proklamasi kemerdekaan ke seluruh pelosok indonesia baik melaui sarana Pos, Telepon, maupun Telelegraf.

Karena meiliki nilai historis yang tinggi dan memiliki kontribusi yang besar bagi kemerdekaan Bangsa Indonesia, maka sejarah pos sangatlah penting untuk dikenalkan kembali, mengingat buku yang membahas tentang sejarah pos di Indonesia masih jarang ditemui.

Untuk membuat sebuah buku pengetahuan tentang sejarah pos yang menarik, maka diperlukan teknik penyampaian yang informatif dan mudah untuk dipahami, Sehingga dipilihlah media komunikasi visual dalam bentuk visual book yang dapat membantu pemahaman pembaca terhadap materi yang dibahas melalui bahasa gambar atau visual. Melalui visual book ini pembaca dapat mempelajari sejarah Pos di Indonesia dengan mudah dan praktis karena buku ini berisi pokok-pokok peristiwa sejarah Pos di Indonesia sejak masa pra-aksara hingga kemerdekaan Republik Indonesia. Data-data tentang sejarah Pos di Indonesia yang akan digunakan sebagai sumber sejarah visual book terlebih dahulu disaring dari seberapa penting dan menariknya kejadian sejarah tersebut dan diurutkan kembali sesuai timeline. Hal ini bertujuan untuk memudahkan pembaca memahami dengan mudah dan cepat isi dari peristiwa sejarah yang diringkas dalam buku ini. Ilustrasi dibuat dengan teknik vector art dengan gaya Flat Design yang modern dan menarik untuk meninggalkan kesan yang membosankan dalam buku sejarah, yang pada umumnya berisi foto-foto lama yang terkadang kurang jelas karena beberapa foto telah rusak karena usia. Dengan diilustrasikan ulang diharapkan foto-foto dokumentasi tersebut dapat direkonstruksi agar lebih jelas dan menarik, sehingga buku ini dapat digunakan sebagai sarana bantu dan referensi utuk mempelajari Sejarah Pos di Indonesia.

\section{DAFTAR PUSTAKA}

\section{Buku:}

[1] Daryanto, S.S, 2000, Kamus Lengkap Bahasa Indonesia, Surabaya: Appolo

[2] Kementrian Pendidikan dan Kebudayaan, Direktorat Jendral Kebudayaan, Direktorat Sejarah dan Nilai Budaya. 2012. Pemikiran Tentang Pembinaan Kesadaran. Sejarah Jakarta: PT.Mitra Agung Sangga Artha.

\section{Pertautan:}

http://www.artikata.com/arti-345775pos.html, diakses pada 23 Mei 2014

http://www.kidnesia.com/Kidnesia2014/DariNesi/Sekitar-Kita/Pengetahuan-

Umum/Surat-Menyurat-di-Indonesia, diakses pada 13 Mei 2014

http://www.posindonesia.co.id/index.php/pro fil-perusahaan/sejarah-pos, diakses pada 13 Mei 2014

http://www.posindonesia.co.id/index.php/pro fil-perusahaan/sejarah-pos, diakses pada 13 Mei 2014 
